\title{
Rethinking and Reframing Leadership of Historically Black Colleges and Universities: A Distributed Perspective
}

\author{
De Witt Scott ${ }^{1}$, Resche Hines ${ }^{2}$ \\ ${ }^{1}$ Education in Educational Leadership Department, Chicago State University, Chicago, USA \\ ${ }^{2}$ Institutional Research and Effectiveness Department, Stetson University, DeLand, USA \\ Email: fivepercent11@gmail.com
}

Received 18 May 2014; revised 20 June 2014; accepted 30 June 2014

Copyright (C 2014 by authors and Scientific Research Publishing Inc.

This work is licensed under the Creative Commons Attribution International License (CC BY). http://creativecommons.org/licenses/by/4.0/

(c) (i) Open Access

\begin{abstract}
In recent years, many Historically Black Colleges and Universities (HBCUs) have experienced a decline in enrollment and prestige. Several leading scholars attribute this to societal shifts that have challenged the historical mission of HBCUs. Higher education's current environment demands a transformation of how HBCU leadership is administered if these institutions are to survive. Distributed leadership focuses primarily on the process of leadership rather than the traditional perspective of a single, dynamic leader at the top of a hierarchical chain, as is typically experienced at most HBCUs. This paper will contend that distributed leadership is an effective leadership strategy for the maintenance, sustainability, and advancement of HBCUs.
\end{abstract}

\section{Keywords}

HBCUs, Higher Education Leadership, Distributed Leadership, Higher Education Administration

\section{Introduction}

The objective of this article is to present solutions to what has become a critical issue at America's Historically Black Colleges and Universities (HBCUs): inefficient leadership. Many of the nation's HBCUs are on the brink of destruction due to continual mismanagement of fiscal, human, and academic resources. Considering the historical mission of these universities to serve, educate, and prepare American society's most underserved populations, particularly African Americans, it is imperative that these institutions make the necessary adjustments that will enable their survival into the future. With an influx of changes in the nature in which the higher education industry is evaluated and funded, leaders of HBCUs will need to discard the management tactics that have 
placed them in the predicament that they now find themselves and embrace new ways of leading and governing. This paper presents a model of change that can be helpful to leaders who desire to improve their institutions. Distributed leadership is proposed as a way to address these concerns and position HBCUs to be the top-level institutions that they were created to be.

Examined throughout the paper is the current state of leadership of HBCUs, the details of distributed leadership, and what distributed leadership would look like if practiced at an HBCU. It must be understood that while distributed leadership is proposed as a solution to the management problems at these institutions, it is not the only solution. There are other leadership models and designs that may be effective in improving the plight of HBCUs. Some of these designs are briefly explained in this paper, but a detailed breakdown of them all is beyond the scope of this work. The primary objective of this article is to outline how and why distributed leadership would be an effective leadership style for HBCUs.

\section{Current State of Leadership of HBCUs}

Historically, the organizational structure of HBCU's has lent itself to be the model of inefficiencies and constantly mounting resistance to organizational change. There has been a lack of data-driven decision-making processes that have led many to wonder about the dynamic between an institution's culture, politics, and leadership ability to implement effective management strategies for improved performance. Fiscal mismanagement, due primarily to a lack of an institutional level compliance programs, has led to investigations by the United States Department of Education, and, in extreme cases, suspension of Title IV funding. Over the past twenty years, across most HBCU's there have been multiple cases detailing the failure of leadership to manage these institutions responsibly. The most infamous example of fiscal mismanagement was the case of Morris Brown University.

With limited resources both, financially and with human capital, the structure of HBCUs often allows for its leaders to have an over-extension in the breadth of control with the lack of depth in critical areas. The nature of having limited resources and overreaching power for institutional leadership have caused HBCUs to become deeply entrenched in protecting outdated institutional cultures (Evans, Evans, \& Evans, 2002). These cultures are often characterized by departmental systems and division silos whose main purpose results in the facilitation of maintenance of status quo operational structures, which are oftentimes at odds with the core university mission and vision statements. One can argue that this characteristic is not unique to HBCUs. To be fair, the siloed structure of higher education has been a restriction in the healthy transformation of these institutions from their $20^{\text {th }}$ century iteration of creating productive, educated leaders of society, to the current state of transparency and accountability. As with most institutions designed to support Black society within the United States, when the pressure is felt by the society at large the effect on Black institutions is twenty-fold.

There have been many historical societal issues that have hindered the development of a number of HBCUs. These issues mirror many of the challenges that have impacted the Black community within the United States as a whole (Brown \& Davis, 2001). Underfunding, fiscal mismanagement, poor leadership, and lack of long term planning have been just a few of the issues that have plagued many HBCUs and their leaders. Dysfunctional leadership and institutional traditions dominate at the majority of HBCU's, impeding the process of change and demanding specific strategies that address certain elements of academic culture (shared governance etc.) (Gasman, 2009).

Over the past forty years, HBCUs have experienced a steady decline in enrollment due to a number of factors. This decline in enrollment is often blamed on societal shifts that have negatively affected the mission of HBCUs which has traditionally been the creation, development, and education of the Black middle class. The impact of desegregation forging "black flight" of a significant portion of the most talented Black students from HBCUs to PWIs is one of the leading factors that have impacted enrollment. Over the past 60 years, the student profile of HBCUs has shifted from 100\% African American in the 1950's to 80\% in 2002 (Allen \& Jewell, 2002). The changing diversity of the student population presents another challenge to the future of HBCUs. Today the 105 HBCUs enroll $11 \%$ of Black students in the United States, yet they represent less than 3\% of colleges and universities in the country (Abelman \& Dalessandro, 2009). The recent economic downturn in the United States is another significant factor that has impacted enrollment at Historically Black Colleges and Universities.

Reversing the issues stated above will require new, innovative leadership practices that challenge the traditional ways in which HBCUs are governed. Practices that have proven to be inefficient, not driven by data, det- 
rimental to the financial and academic health of the institution, overreaching, and contributing to declining enrollment will have to be investigated, addressed, and removed. New leaders with an understanding of the changing dynamics of society, its workforce, and education overall will need the power and opportunity to make relevant changes. Without an adjustment in leadership style and personnel, HBCUs will continue to suffer and, after some time, possibly become obsolete.

\section{Alternative Theories of Leadership}

Leadership of HBCUs has often been characterized by fiscal mismanagement, micromanagement of Boards of Trustees, and cronyism. For the long-term survival of HBCUs, a clearly defined model of effective leadership needs to be implemented within these institutions. To begin to develop this leadership model a review of the seminal leadership ideology must be undertaken to determine if these leadership designs will be adequate for HBCUs. The leading theories of organizational leadership can be categorized into the following topical areas: trait theories and power and influence theories.

\subsection{Trait Theories}

Trait theories take the position that leaders inherit certain qualities and traits that make them better suited to lead. Trait theories often identify particular personality or behavioral characteristics shared by leaders. Many critics of this leadership ideology make the point that if particular traits are key features of leadership, how are these sorts of leaders identified? Is it possible to develop key leadership traits or are these traits inherited? These questions and others have been used to discredit the use of trait theories to explain leadership.

In contrast, trait theories take the position that effective leaders share a number of common personality traits. Early trait theorists (Stogdill, 1948; Mann, 1959) indicated that effective leadership is an innate, instinctive quality one does or does not have. Later theorists who studied this leadership ideology took the position that leadership development is more about learning what leadership qualities are developed within organizational leaders and their peers (Avolio, Sosik, Jung, \& Berson, 2003). Foundational works around trait theories have added to the field of leadership core identity traits and qualities of effective leadership (i.e. integrity, empathy, assertiveness, good decision-making skills, and likability). However, there has been little evidence to link specific combinations of the aforementioned traits and their ability to prove effective leadership in higher education institutions. Many theorists argue that traits are external behaviors that emerge from the things going on within our minds and within our environment. The combination of the environment and these internal beliefs and processes shape the behaviors of leaders which are the foundations for effective leadership.

\subsection{Power and Influence Theories}

Power and influence theories are based on the principle that different leaders use power and influence to accomplish logistical goals, and that impactful leadership styles emerge as a result. The leading work of this leadership ideology, presented by French and Raven (1959), is known as the Five Forms of Power. This model highlights three types of positional power-legitimate, reward, and coercive-and two sources of personal power-expert and referent (your personal appeal and charm). The model suggests that using personal power is the better alternative, and that you should work on building expert power (the power that comes with being a real expert in the job) because this is the most legitimate source of personal power. Another leadership style that uses power and influence is transactional leadership. This approach assumes that people do things for reward and no other reason. Therefore, it focuses on designing tasks and reward structures. While this may not be the most appealing leadership strategy in terms of building relationships and developing a highly motivating work environment, it often works, and leaders in most organizations use it on a daily basis to get things done.

When applying a critical leadership theorist lens to leadership of HBCUs, many examples indicate that the traditional characteristic of many presidents and chancellors of HBCUs is that of top-down decision-making structures. Specifically, the behavior traits that have been salient across several generations of HBCU leadership and organizational structures can be characterized with the principles of making decisions independently of organizational input with the belief that presidents have single authority for decision making at these institutions. Many researchers have found that the predominant leadership style at HBCUs has been authoritarian in nature. This leadership practice is often cited in the literature as leadership structures in which a clear division is struc- 
tured organizationally between the leader and his/her direct reports. In contrast, many scholars of organizational leadership describe effective leadership style as the manner and approach of providing direction, implementing plans, and motivating staff. Researchers found that decision-making was less creative under authoritarian leadership. Authoritarian leadership is best applied to situations where there is little time for group decision-making or where the leader is the most knowledgeable member of the group.

In leadership dependent organizations such as HBCUs, how leaders behave affects the performance of all sectors of the organization. Researchers have realized, though, that many of these leadership behaviors are appropriate at different times. For the long-term sustainability of HBCUs, the next generation of leaders will be those that understand how to use many different behavioral styles and choose the right style for each situation. Many researchers believe that transformational leadership, is the most effective style to use in most higher education institutions, specifically in HBCUs.

\section{Detailed Explanation of Distributed Leadership}

\subsection{What Is Distributed Leadership?}

Distributed leadership is loosely defined as "a form of shared leadership that is underpinned by a more collective and inclusive philosophy than traditional leadership theory that focuses on skills, traits, and behaviors of individual leaders" (Jones, Lefoe, Harvey, \& Ryland, 2012: p. 71). At its core, it is an ideology that focuses more on the process of leadership rather than the work of a dynamic, charismatic leader at the top of a hierarchical chain (Harris, Leithwood, Day, Sammons, \& Hopkins, 2007).

Higher education as a whole has undergone, and continues to undergo, numerous changes in its strategic, economic, structural, and philosophical composition. These changes have taken place at a rapid pace and have caused industry leaders to reexamine the way institutions are led, situated, and defined in the current social context. Such a reexamination has led many leaders to explore more collegial, participatory modes of leadership and decision-making on the nation's campuses.

In the midst of this search, the concept of distributed leadership has been broached frequently. Its ideological foundations are closely aligned with the concepts of shared, collective, collaborative, emergent, co- and democratic leadership (Bolden, 2011; Harris et al., 2007). These concepts are very similar to distributed leadership and, in practice, are usually merged to some degree to form a somewhat "hybrid" form of leadership (Gosling, Bolden, \& Petrov, 2009; Gronn, 2009; Bolden, Petrov, \& Gosling, 2008).

With distributed leadership, emphasis shifts to a rather "post-heroic" position that allows one to view the entire organization as having an integral part to play in leadership (Bolden, Petrov, \& Gosling, 2009; Harris et al., 2007; Bolden, 2011). Woods, Bennett, Harvey, and Wise (2004) identify distributed leadership as consisting of three distinctive characteristics: emergent property, openness of boundaries, and leadership according to expertise. In distributed leadership, emergent property is defined as an assembly of individuals working and collaborating to bring about the leadership process. Such a method contrasts with the popular view of leadership as arising from one individual in a formal, appointed position. Openness of boundaries refers to distributed leadership authorizing the expanding of the traditional cadre of organizational leaders. With fluid boundaries, leadership responsibility exists across institutional sections and levels, and can be conducted in a horizontal or bottom-up design as opposed to always a top-down approach (Bolden et al., 2008; Harris et al., 2007). Lastly, distributed leadership evokes the perspective that expertise is not just limited to the formal leader at the top but also lies in numerous organizational members (Harris et al., 2007; Bolden et al., 2008). With such dispersed expertise, distributed leadership contends that a quality leadership process allows individuals who have expertise in the situation at hand to lead and make decisions regardless of their formal title or position. Leadership according to expertise dispels the popular notion that all authority and governance should come from the same person regardless of the issue. These three traits serve as the basis of distributed leadership.

\subsection{Review of Current Literature}

Empirical data and recorded outcomes of distributed leadership implementation are scarce, particularly in regards to higher education governance (Harris et al., 2007). Although the concept has experienced a swift hike in popularity over the past fifteen years as a research topic, there is still not much evidence on its effectiveness or 
weaknesses. This research also remains mainly concentrated, and of higher interest, in the UK than in the US (Bolden, 2011). Research has shown that the majority of scholarly works that refer to distributed leadership oftentimes address the concept alongside related theories of emergent, co-, and collaborative leadership (Bolden, 2011). This same research revealed that publications that refer to distributed leadership without connection to the above related concepts are "significantly" greater in the UK than the US, and that $68 \%$ of these articles were published in education related journals (Bolden, 2011: p. 255).

The limited research on distributed leadership in the US has centered almost exclusively on primary and secondary education (Jones et al., 2012). Distributed leadership at this level has stressed the teacher as a leader not only in the classroom, but throughout the school building and in terms of decision-making as well (Jones et al., 2012; Harris et al., 2007). Acknowledgement is also given to the importance of informal leaders and networks and the influence these individuals have on the culture, morale, and climate of the school building.

Existing research on distributed leadership in the UK focuses mainly on higher education, but has yet to pinpoint a single, universal design that is successful. What has been determined though is that in order for distributed leadership to even begin to be successful, leaders must establish a context or an atmosphere for scholars and staff to satisfy and expand upon their potential (Jones et al., 2012). Organizational leaders are advised to grant autonomy to their constituents and encourage participation and collaboration throughout their campuses if distributed leadership is to be successful and sustainable over time.

According to the current literature, there is no consensus on a clear definition of distributed leadership. Despite this, Gosling et al. (2009) state that "everyone seems to know what it means" (p. 4). There is a shared understanding that distributed leadership is chiefly a fluid, informal, and widely dispensed model of leadership that puts the process as the center of attention rather than the talent and skills of a head executive or entitled leader (Bolden et al., 2008; Bolden et al., 2009; Gosling et al., 2009).

\subsection{Implications for Implementation in Higher Education}

Higher education has witnessed many changes and challenges to the field in recent decades. There has been increased pressure from the private sector for better-prepared graduates, a push from the public for more accountability on its governance structures, dwindling financial support from government, and increased tuition and debt among its graduates that leave students and parents questioning the necessity of a college education. Such issues have forced education leaders and policymakers to rethink the way these schools are led and governed. What has resulted is an escalation in the replacement of traditional forms of higher education leadership with more private sector-like principles of management and leadership (van Ameijde, Nelson, Billsberry, \& van Meurs, 2009). Quickly disappearing are the collegial, autonomous forms of leadership that have been traditionally associated with higher education, and inserted is the administering and oversight of measured outcomes, department audits, and validation of disciplines and personnel. Such a shift has created increased administrative control and caused tension between administrators and university professors, students, and staff (van Ameijde et al., 2009).

Obvious to most scholars of higher education leadership is that new forms and approaches of leadership are necessary to address the quickly-changing pace of society and the challenges these changes create. The private sector-based leadership changes implemented so far have been unsuccessful. They have been seen as a bit idealistic and promoted by many policymakers who do not have a sufficient understanding of education. As van Ameijde et al. (2009) state, the problem is "exacerbated by the fact that higher education institutions have unique cultural characteristics which make the translation from management principles derived from the private-sector to a higher education context problematic" (p. 764).

Such issues as those stated above point to the clear need for the adoption of administration and governance techniques that can fit properly into this context. A process is needed that can amicably connect the traditions of collegially and the increased demands of accountability and efficiency. Distributed leadership can serve that purpose. Its principles of welcomed input, fluid boundaries, and experts leading particular situations mesh well with the notions of collegiality and autonomy (van Ameijde et al., 2009). Also, distributed leadership, with its involvement of a diverse set of leaders throughout the campus, would bring about greater accountability from the university as a whole and a checks-and-balances system among the "expert" leaders than can demand and validate efficient practices. If implemented correctly, it can prove to be a significant step in preparing universities to meet the challenges of the future. 


\section{Applying Distributed Leadership to HBCUs}

\subsection{What It Would Look Like at an HBCU}

At the core of distributed leadership is the idea of having capable, adequate individuals from each constituency playing an integral and significant part in a university's decision-making processes. On an HBCU campus, distributed leadership would manifest itself in this form. Traditional beliefs about HBCU leadership often center on an autocratic leadership style that puts severe limits on faculty participation (Lewis, 2011). Inclusion of other constituency groups — students, staff, department chairs, community members, and alumni-is rarely recognized collectively from these universities.

State funding reductions, endowment funding decreases, declining alumni donations, significant numbers of faculty nearing retirement, increased tuition costs, and increased enrollment of underprepared students have forced HBCUs into a difficult position. These challenges demand that HBCU leaders address complicated and complex issues instantaneously (Lewis, 2011). In order to do this effectively, new leadership models will have to be implemented.

\subsection{Why Distributed Leadership for HBCUs?}

Distributed leadership offers a process that can help HBCUs address their needs. With all constituency groups involved in meaningful ways, odds that all issues will be sufficiently addressed will increase, communication across institutional levels will improve, and confusion will lessen. Presidents will not have a monopolizing control on all power and decision-making. His/her reasons for making certain choices will be forced to become more transparent, inclusive, and therefore aligned with the group he/she is leading.

Considering the unique structural, historical, and cultural nature of HBCUs, it is imperative that the leadership style of these institutions be unique as well. HBCUs, generally, are far more autocratically governed than average American universities. With minimal fiscal resources and a focused mission dedicated to delivering postsecondary education to many students who are underprepared, leadership styles at these institutions cannot afford to bestow power to just one or a handful of people at the top of an administrative food chain. These institutions must have competent, committed leaders at every institutional level providing high quality insight, knowledge, and direction to all constituents connected with the campus. HBCUs were always schools that were deeply connected to the people and communities that were marginalized by larger society. This is still the case in contemporary times. In order for HBCUs to hold true to this foundational mission, a different, creative oversight model needs to employed that is totally dissimilar to what is experienced at most other universities. That model is distributed leadership.

To appropriately explain how distributed leadership would unfold on a college campus, as well as best ways for implementation, a detailed analysis for each constituency group is given below.

\subsubsection{Faculty}

In regards to faculty, distributed leadership would create situations that aren't normal on HBCU campuses. Gone would be the token participation of a powerless faculty senate. With distributed leadership, faculty would elect its best, most competent experts to be its leaders, meet regularly to devise a collective, united agenda, and take the unquestioned lead of all the institution's academic concerns. As experts of the academic life of the university, faculty would lead the university's academic initiatives, make curriculum-based decisions, and have the final word on faculty hiring in their respective departments. Senior administration would be a part of the process, as the goal of distributed leadership is inclusion, not exclusion with a different face. The difference is that final approval would not be in the hands of the president or senior administrators but in that of the faculty. Faculty will be compelled to involve all constituents in their decision-making meetings and acknowledge their concerns.

\subsubsection{Students}

Distributed leadership implementation among the student body would take place primarily in the classroom. Student leaders, as selected by the students themselves, would have a greater, but not absolute, say on the choice of textbooks for classes. Oftentimes, a textbook is selected for a class for reasons that have nothing to do with advancing student learning. Students should be provided with options and be allowed to choose which book best suits what the students want to learn. In addition, students should also be presented with assignment/project 
choices for the semester by their instructors and allowed to choose from the available options. Having students' input shows that the institution cares about the students' opinions, values them as aspiring intellectuals, and are committed to preparing them to become leaders.

\subsubsection{Deans/Department Chairs/Mid-Level Administrators}

Deans and department chairs serve a very vital function at HBCUs, and in higher education institutions as a whole. They are often the liaisons between faculty and senior administration. In autocratic-governed institutions, it is often their value and service that is most underappreciated. Distributed leadership can empower them to take control of their responsibilities without the concern of upper-administration meddling in and micromanaging their affairs. With distributed leadership, deans could be given final jurisdiction on how department- and college-level budgets are used and will not need approval or consent from upper-administration. The last line of the tenure approval process could also rest with the dean position. Currently, tenure appointments are usually subjected to final acceptance or rejection decisions by the president. Placing this power in the hands of deans seems the most logical thing to do considering that the faculty member works most closely with the deans and chairs and not the president. These are things that can be addressed and improved through distributed leadership.

\subsubsection{Senior-Level Administrators/Board of Trustees}

Senior-level administrators are not stripped of all their power when distributed leadership is applied. Responsibility is, instead, redirected and shared across institutional lines. When applying distributed leadership, it is still best that senior administration has control over admissions practices, setting tuition, hiring deans, dismissal of students for discipline-related issues, and fundraising. Allocating budgets to individual colleges should also be the responsibility of senior administration in a distributed environment. Input from all constituency groups should be included in every decision made, as well reasons should be given and publicized indicating why a certain decision would be made.

\subsubsection{Community Members}

Community leaders and activists should have significant input in any initiative promoted by the university aimed at improving and enhancing the community. Religious leaders, respected community elders, and parents of current and past students should have their voices heard on issues such as campus expansion, community organizing, and some weekend events. Distributed leadership will give these community members a voice and strengthen ties between the school and community.

A key aspect of successful distributed leadership on HBCU campuses will be disclosure and transparency. When any and all decisions are made it should be mandatory for any group that has made the decision to publicize their decision, reasons for making such a decision, all constituency groups that were involved, and objections that were raised in opposition to the decision. This will allow anyone who is interested to see the decisionmaking process and why leaders arrived at any given decision, and eliminate the air of secrecy often experienced around the centralized, authoritarian, hierarchical leadership at most HBCU institutions.

The above breakdown displays how distributed leadership would be enacted on each stakeholder level. A leadership process that occurs in this manner gives outsiders and higher education policymakers the perspective that HBCUs are attempting to develop themselves as democratic spaces where collegiality and collaboration exists. National higher education leadership bodies such as the US Department of Education and national and regional accrediting agencies will realize that HBCUs are changing to meet the inevitable challenges that will continue to confront these institutions throughout the $21^{\text {st }}$ century. Citizens will be more inclined to explore sending their children to HBCUs if these schools can display, through their successful distributive leadership implementation, that their children will be valued as contributors and participants of a broader learning community that is focused on working together to achieve its goals. Such a process will be a significant step toward reversing the perspective that HBCUs are inferior institutions and incapable of producing top-level graduates and scholars.

\section{Conclusion}

If HBCUs are to remain viable and sustainable into the future, new leadership processes will need to be implemented. Autocratic/authoritarian practices will have to be eradicated and faculty, staff, students, and community members will have to be included in the leadership process in meaningful ways. Distributed leadership offers 
this opportunity. Succinctly defined, distributed leadership is the process of dispensing leadership responsibility among different members of the institution rather than reserving all responsibility for one, sole leader at the top of a hierarchical chain. HBCUs that take steps toward a distributed leadership approach will position themselves to excel and become prominent institutions for many decades to come.

\section{References}

Abelman, R., \& Dalessandro, A. (2009). The Institutional Vision of Historically Black Colleges and Universities. Journal of Black Studies, 40, 105-134. http://dx.doi.org/10.1177/0021934707307828

Allen, W. R., \& Jewell, J. O. (2002). A Backward Glance Forward: Past, Present, and Future Perspectives on Historically Black Colleges and Universities. The Review of Higher Education, 25, 241-261. http://dx.doi.org/10.1353/rhe.2002.0007

Avolio, B. J., Sosik, J. J., Jung, D. I., \& Berson, Y. (2003). Leadership Models, Methods, and Applications. In W. C. Borman, D. R. Ilgen, R. J. Kilmoski, \& I. B. Weiner (Eds.), Handbook of Psychology (pp. 277-308). Hoboken, N. J.: John Wiley \& Sons, Inc. http://dx.doi.org/10.1002/0471264385.wei1212

Bolden, R. (2011). Distributed Leadership in Organizations: A Review of Theory and Research. International Journal of Management and Reviews, 13, 251-269. http://dx.doi.org/10.1111/j.1468-2370.2011.00306.x

Bolden, R., Petrov, G., \& Gosling, J. (2008). Tensions in Higher Education: Towards a Multi-Level Model of Leadership Practice. Higher Education Quaterly, 62, 358-376. http://dx.doi.org/10.1111/j.1468-2273.2008.00398.x

Bolden, R., Petrov, G., \& Gosling, J. (2009). Distributed Leadership in Higher Education Rhetoric and Reality. Educational Management Administration \& Leadership, 37, 257-277. http://dx.doi.org/10.1177/1741143208100301

Brown, M. C., \& Davis, J. E. (2001). The Historically Black College as Social Contract, Social Capital, and Social Equalizer. Peabody Journal of Education, 76, 31-49. http://dx.doi.org/10.1207/S15327930PJE7601_03

Evans, A. L., Evans, V., \& Evans, A. M. (2002). Historically Black Colleges and Universities (HBCUs). Education, 123, 3-16.

French, J. R. P., \& Raven, B. H. (1959). The Basis of Social Power. In D. Cartwright (Ed.), Studies in Social Power (pp. 150-167). Ann Arbor, MI: Institute for Social Research.

Gasman, M. (2009). Historically Black Colleges and Universities in a Time of Economic Crisis. Academe, 95, 26-28.

Gosling, J., Bolden, R., \& Petrov, G. (2009). Distributed Leadership in Higher Education: What Does It Accomplish? Leadership, 5, 299-310. http://dx.doi.org/10.1177/1742715009337762

Gronn, P. (2009). From Distributed to Hybrid Leadership Practice. In A. Harris (Ed.), Distributed Leadership: Studies in Educational Leadership (pp. 197-217). New York, NY: Springer. http://dx.doi.org/10.1007/978-1-4020-9737-9_11

Harris, A., Leithwood, K., Day, C., Sammons, P., \& Hopkins, D. (2007). Distributed Leadership and Organizational Change: Reviewing the Evidence. Journal of Educational Change, 8, 337-347. http://dx.doi.org/10.1007/s10833-007-9048-4

Jones, S., Lefoe, G., Harvey, M., \& Ryland, K. (2012). Distributed Leadership: A Collaborative Framework for Academics, Executives, and Professionals in Higher Education. Journal of Higher Education Policy and Management, 34, 67-78. http://dx.doi.org/10.1080/1360080X.2012.642334

Lewis, V. M. (2011). Faculty Participation in Institutional Decision Making at Two Historically Black Institutions. $A B N F$ Journal, 22, 33-40.

Mann, R. D. (1959). A Review of the Relationship between Personality and Performance in Small Groups. Psychological Bulletin, 66, 241-270. http://dx.doi.org/10.1037/h0044587

Stogdill, R. M. (1948). Personal Factors Associated with Leadership: A Survey of the Literature. Journal of Psychology, 25, 35-71. http://dx.doi.org/10.1080/00223980.1948.9917362

van Ameijde, J. D., Nelson, P. C., Billsbery, J., \& van Meurs, N. (2009). Improving Leadership in Higher Education Institutions: A Distributed Perspective. Higher Education, 58, 763-779. http://dx.doi.org/10.1007/s10734-009-9224-y

Woods, P. A., Bennett, N., Harvey, J. A., \& Wise, C. (2004). Variabilities and Dualities in Distributed Leadership: Findings from a Systematic Literature Review. Educational Management Administration \& Leadership, 32, 439-457. http://dx.doi.org/10.1177/1741143204046497 
Scientific Research Publishing (SCIRP) is one of the largest Open Access journal publishers. It is currently publishing more than 200 open access, online, peer-reviewed journals covering a wide range of academic disciplines. SCIRP serves the worldwide academic communities and contributes to the progress and application of science with its publication.

Other selected journals from SCIRP are listed as below. Submit your manuscript to us via either submit@scirp.org or Online Submission Portal.
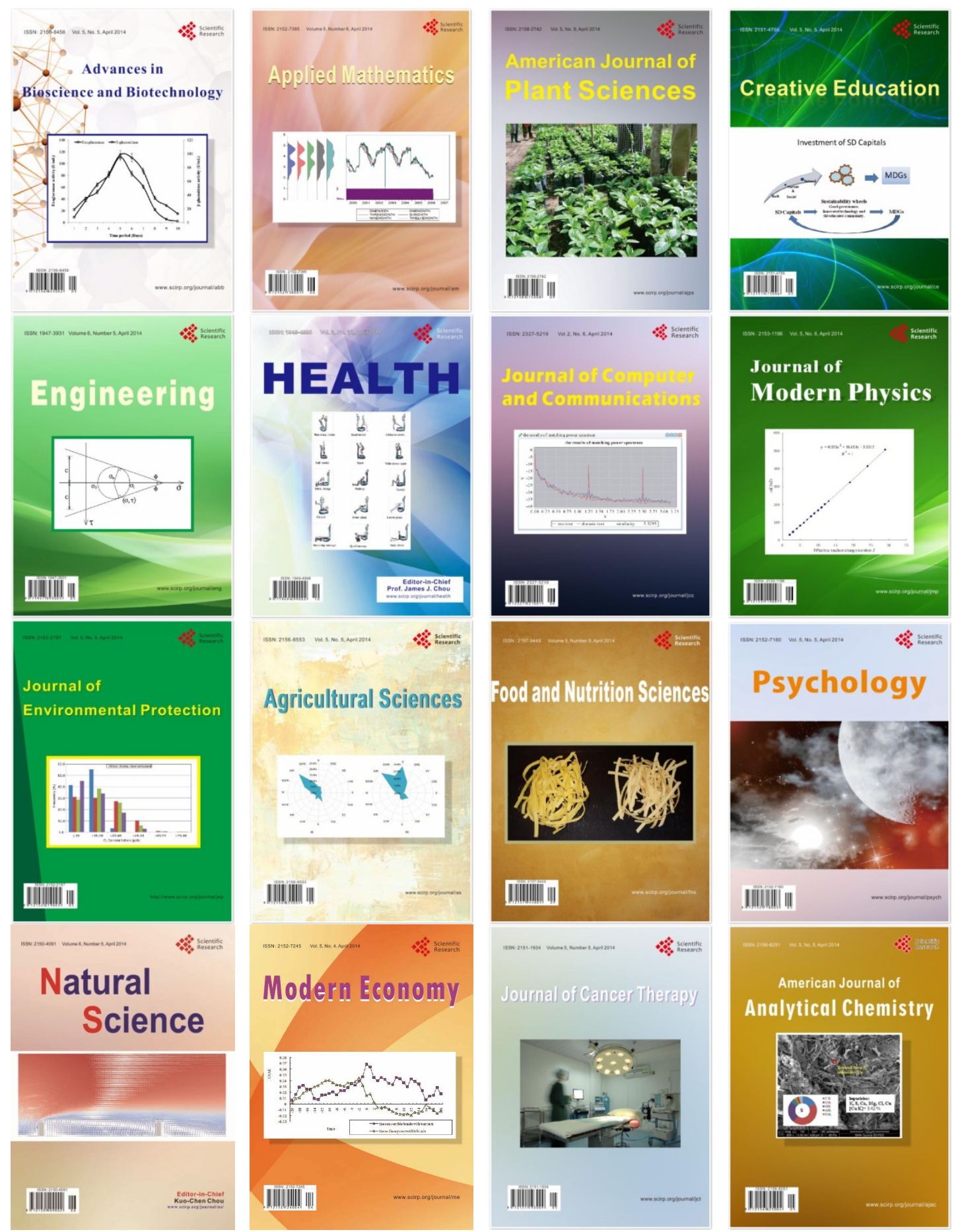